\title{
The Compliance of Road Users with the Speed Limit at School Zones on Federal Road FT50 (KM0-KM23)
}

\author{
Raha Abd Rahman, Nazurah Lausman, Lim Wei May, Nordiana Mashros, Mohd Idrus Bin \\ Mohd Masirin, Mohammad Sukri Bin Mustapa, Mohd Farid Hassan
}

\begin{abstract}
Driving speed at school zone is an important concern on road safety. In Malaysia, the speed limit of $30 \mathrm{~km} / \mathrm{hr}$ is mandatory at school zone. Thus, this study aims to investigate the compliance of road users towards the speed limit and the signage at school zone and determine the factors of noncompliance. The research was conducted along the Federal Road of Batu Pahat and Ayer Hitam Johor FT050 (KM0-KM23) where 7 schools were situated. Methods used are spot speed and site visit as well as obtaining the road accident statistics from the Royal Malaysian Police. The data collected was analysed, those above $85^{\text {th }}$ percentile speed and below $15^{\text {th }}$ percentile speed did not comply with the speed limit imposed $30 \mathrm{~km} / \mathrm{hr}$ signs. The results show most of the road users failed to obey the $30 \mathrm{kn} / \mathrm{hr}$ speed limit at all the study locations and the factor affecting this are aggressive driving and signage not meeting the required standards. As consequences, there in an increasing trend of road accidents along FT050.
\end{abstract}

Keywords: Compliance; Speed Limit; Signage; School Zone.

\section{INTRODUCTION}

Road accidents involved school children are common among the school zones in Malaysia. In 2015, among the 286 accidents occurred in school zones 18 cases were fatalities. According to accident statistics from the Royal Malaysian Police 2015, Malaysia recorded a total of 489,606 road accidents [1] with Federal route FT050 Batu Pahat-Kluang-Mersing ranked the second highest number of road accidents in Malaysia. In the Malaysian Design Guide for safety at school facility [2], pedestrian had $90 \%$ chances of being safe from accidents for driving speed $30 \mathrm{~km} / \mathrm{hr}$ or below. It also reported that when the driving speed increase to $45 \mathrm{~km} / \mathrm{hr}$ and above, the chances of being safe from accident reduced to $50 \%$. When the driving speed increases

Revised Manuscript Received on April 19, 2019.

Raha Abd Rahman, Department of Civil and Environmental Engineering, Universiti Tun Hussein Onn Malaysia, Parit Raja, Batu Pahat, Johor, Malaysia.

Nazurah Lausman, Department of Civil and Environmental Engineering, Universiti Tun Hussein Onn Malaysia, Parit Raja, Batu Pahat, Johor, Malaysia.

Lim Wei May, Department of Civil and Environmental Engineering, Universiti Tun Hussein Onn Malaysia, Parit Raja, Batu Pahat, Johor, Malaysia.

Nordiana Mashros, School of Civil Engineering, Faculty of Engineering, Universiti Teknologi Malaysia, Skudai Johor, Malaysia

Mohd Idrus Bin Mohd Masirin, Department of Civil and Environmental Engineering, Universiti Tun Hussein Onn Malaysia, Parit Raja, Batu Pahat, Johor, Malaysia.

Mohammad Sukri Bin Mustapa, Faculty of Mechanical and Manufacturing Engineering, Universiti Tun Hussein Onn Malaysia, Parit Raja, Batu Pahat, Johor, Malaysia.

Mohd Farid Hassan, Pejabat Tanah Kluang, Kluang, Johor, Malaysia from $30 \mathrm{~km} / \mathrm{hr}$ to $50 \mathrm{~km} / \mathrm{hr}$, the probability of fatalities for pedestrian multiple by 8 folds [3]. Fig. 1 illustrates the three contributing factors to road accidents [4], mainly due to human factors, vehicle factors and road environment factors. Human factors itself attributes $95 \%$ to traffic or road accidents, human behaviour such speeding, aggressive driving and negligence are risking the safety on the road [5]. When driving speed vary drastically, there are more instances of unsafe passing, rear-end collisions and weaving on multilane roads. It is strongly recommended to reduce the driving speed at school zone. The reduction of speed limit at school zones designed to increase the safety of the road users outside the school while taking into consideration the account for speeding, high traffic volume and the school peak hours. The priority of the children safety is the main factor for the reduction of the speed limit. The speed limit displayed on the speed limit signage is secured as safe and appropriate for drivers to drive especially during the peak hours of school zone. Thus, this study aimed to identify the compliance of the road users towards the speed limit located at school areas.

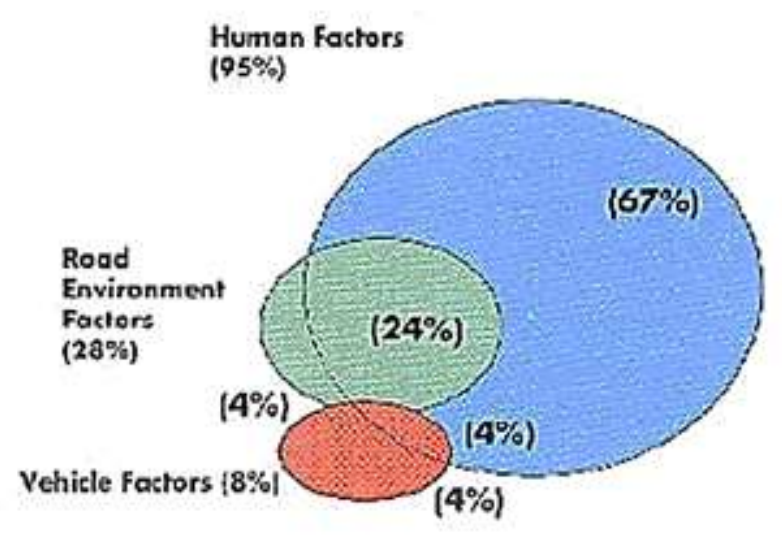

Fig. 1. Factors contributing to road accidents. Source [4]

\section{LITERATURE REVIEW}

\section{School Zones in Malaysia}

The locations of the schools are located on the major road where the statutory speed limit are fixed at $90 \mathrm{~km} / \mathrm{h}$ for federal road. For safety reasons, road authority established the posted speed limit for school zones at $30 \mathrm{~km} / \mathrm{hr}$. The

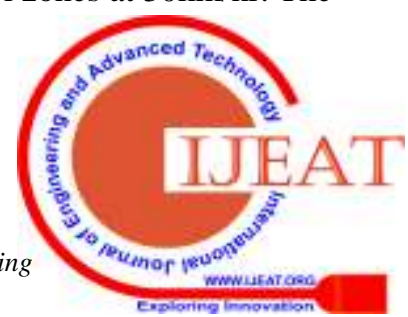


typical school sessions in Malaysia is in the morning, starting at $7.30 \mathrm{am}$ and ends at $1.00 \mathrm{pm}$. The second session is in the afternoon, starting at $1.00 \mathrm{pm}$ and ends around 6.30 $\mathrm{pm}$. The peak hour is where there is the most manoeuvre of venerable road users especially school students are around $7.00 \mathrm{am}$ in the morning, $1.00 \mathrm{pm}$ in the afternoon, and 7.00 $\mathrm{pm}$ in the evening. Around these hours with an hour deviation, there are children departing and arriving from school, where there are many interaction between students and vehicles, exposing them to any risk that will endanger their safety. To ensure the road users are aware of the school zones speed limit, signage, signalised crossing facilities, traffic calming measure such as speed hump and transverse bars are installed to warn drivers driving through the school zones about the speed reduction. There are also other facilities such as zebra crossing, pedestrian bridges and traffic wardens to help in the safe crossing of children and to mitigate the bustling traffic. Despite all this measure, accidents still at the alarming level in school zones, study found to be the inappropriate behaviour of pedestrian and drivers' failure to notice the presence of school zones or students within the school zones.

\section{Speed Limit}

Speed limits reflect the sensible behaviour that should be complied by the majority to effectively manage the risk on road. For the selection of preferred speed of travel, human behaviour is the top influential element. The behaviour of not conforming to the reflected road characteristics are the adverse results of rash decisions and dangerous driving. The two type of speed limits are statutory speed limits and post speed limits [3]. Statutory speed limits also known as national speed limits are established by legislatures to a specific road which are enforced by law and are applicable even if the speed limit sign is no posted. Whereas posted speed limits also known as regulatory speed limits are those sign posted along the road. Posted speed limits can be established the same as or adjusted to certain limit differed from the statutory speed limits.

Speeding is driving that exceeded the posted speed limit or driving too fast under the prevailing conditions. This is the primary crash causation factor around the world and it contributes to one third of fatal crashes. In Malaysia, speeding is one of the main road safety problems and contributes as an aggravating factor in most crashes. The $15^{\text {th }}$ percentile and $85^{\text {th }}$ percentile speed are widely used as a cut-off point in speed limits in traffic. Between the $15^{\text {th }}$ percentile and $85^{\text {th }}$ percentile speed are the sample of free flowing vehicles is travelling. The upper and lower $15 \%$ of the speed distribution where the speed either too fast or too slow for the existing conditions. The 15 th percentile and $85^{\text {th }}$ percentile of the distribution of overserved speeds had been the most frequently used method to determine the operating speed which in turn is used as a guide to set the speed limit. In situations where $85^{\text {th }}$ percentile speed is too high for the prevailing conditions, engineering techniques or traffic calming measure could be used to lower vehicle speeds [6].

\section{Factors affecting compliance}

This following subsection will further discuss the three main factor mentioned in the introduction. Human interaction with stimulus while driving on the road use these 4 stages, recognition, comprehension, evaluation and decision. Their behaviour or decision against a situation or stimuli while driving can be influenced by their gender, driving experience and affective state. Besides, depending on the time of the day or the day of the week, human behaviour on road varies. Study by [7] stated that speeding in school zones can be seen more prevalent in the late evening or nights on weekend or early morning during weekdays in school zones, this could be due to the hurriedness in the morning commutes of school arrival compared to the less hectic afternoon school dismissal times. In additional to that, speed choice also could be due to the familiarity of the drivers. [8] found that route familiarity had an impact on the speed choice, driver perception on risk and accident rates, as familiarity on a route will increase the inattention while driving. In an experiment of four consecutive days, the speed progressively increases and settles on a constant value. Even after a distant time, the driver still driving at a relative high speed. The study confirmed the idea of habituation process will eventually influenced the drivers' speed choice, as for aggressive drivers, habituation is more evident with greater speed than cautious drivers. In this habituation process, familiar drivers at times can be overconfidence, overestimating their driving skills and tend to underestimate the risk of accident in hazardous situations. [9] stated that gender also contribute to aggressive driving. Those with more masculine traits tend to experience more trait of anger. Anger has been related to aggressive and risky driving behaviours such as tailgating, worse vehicle control, red running, speeding, driving above speed limit. Angry drivers have been found to violate safety rules and report of higher number of near misses and crashes. It is the social norms of driving behaviour that drivers who engage in risky behaviours such as speeding because they believe that they will not get caught.

The other attribute to road accident is due to the road environment factors as shown in Fig. 2. Lower level of traffic density, vehicles can travel at higher speed, decreasing the compliance with the posted speed limit. Having school zone can be beneficial to reduce crashes in a previously unsafe location or to increase the compliance with posted speeds, but oversaturation of school zone would be detrimental by diverting driver attention from the multiple school zones. This is the same to signage installed in school zones, sign saturation as found by [7], overwhelming presence of stimulus leads to a driver not noticing a particular stimulus, where too many signs in a given area may actually reduce drivers compliance. This is based on the human information processing, if a driver observes too many of the same stimulus, he or she no longer attends to the stimulus with a great deal of attention. The presence of multiple school zones on a driver's route may lead the driver to ignore the zones altogether. The oversaturation of the signage leads to inattention. Traffic signage is significant in regulating road traffic and driver 
behaviour which facilitated by two mechanisms of the traffic sign. There are the early perceptual processing through repetition priming such as symbol signs and the semantic processing influencing the cognitive processes such as the written signs. [10] stated that the installation of traffic signs combined with flashing lights was great in speed reduction compared to having only flashing or text signs.

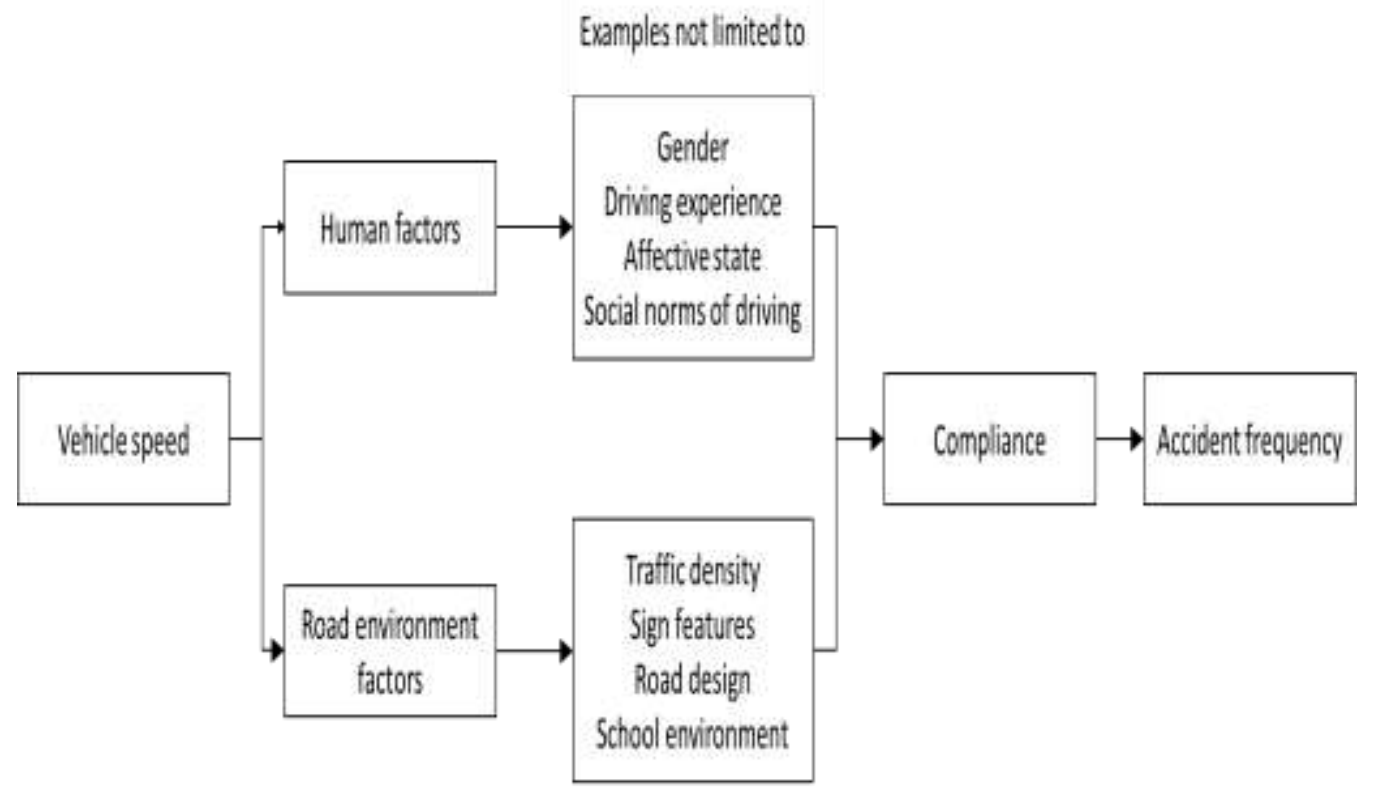

Fig. 2. Summary of factor affecting compliance to speed limit

The authors also mentioned the limitation of the study whether the driver might eventually habituate to the reminder sign and hence question the purpose of traffic signs. The signs features itself also will hinder the conspicuity of traffic signs such as colour, shape, size or graphic boldness. Besides, the road design will also affect the compliance of road users with speed limit and the approaching speed when passing through school zones. This includes the geometrical design such as the length of speed zone and number of lanes, the surrounding development or building types, the number of traffic lights, traffic furniture and facilities, in this case, type of school that may greatly influence driver behaviour on roads. Thus in Malaysia, design plan for signage in school zone is standardised in gazetted guidelines. [11] found that high traffic density have apparent association with high saturation, a 4 lane road type, low mean vehicle speed has higher compliance and lower accident frequency.

Given the increased prevalence of children and other traveling pedestrians at school zone locations, it is important to establish ways to reduce speeding behaviour, There several methods proposed to increase drivers' compliance such as enforcement, appropriate speed zone settings, speed monitoring devices and other interventions. Crossing guard is places especially during school arrival and dismissal. A study by [12] on the speed behaviour on school zone concluded that the implementation of safety management scheme at school zone was neglected by the road users. Besides, people are unable to comply with the speed limit coupled with lack of public awareness are the reason to the effectiveness in the implementation. Therefore, safety education programmes are in cooperated in the schooling education system to improve students' knowledge in traffic safety from their tender age to deal with traffic hazard.

\section{OBJECTIVES}

The main objective of this study is to investigate the compliance of road users towards the speed limit and the signage at school zone. Hence, leading to the second objective which is to determine the factors of noncompliance. The determining variables in this investigation are vehicle speed, speed limit compliance, accident frequency. Vehicle speed are collected on peak hours during school hour operation when there are existence of most manoeuvre around the school perimeter, students going and returning from school.

\section{METHODOLOGY}

The three methods used to conduct this research are site visit, spot speed and questionnaire survey to obtain the data needed for this study. The research location is conducted along federal road FT050 starting at KM0 to KM 23. In this stretch of road the 7 schools situated starting from SK Bukit Soga (KM3 KM4-), SMK Munshi Sulaiman and SMK Tun Aminah (KM5 KM6-), SMK Seri Gading (KM15-KM16) SMK Bypass Pudding (KM20-KM21), SK Pintas Raya (KM17-KM18), SJK (C) Kong Nan (KM24-KM25). Site visit was carried out through the route to collect site condition and signage installation. Spot speed study using radar gun was carried out to identify the speed distribution of the traffic and to generate the frequency distribution for the derivation of the speed percentiles [13] used to compare with the $85^{\text {th }}$ percentile speed for each segment [14]. Speeds are measured during the peak period in the morning, afternoon and evening where there was the most student 
International Conference on Recents Advancements in Engineering and Technology (ICRAET-18) |15th and 16th March 2019|Siddhartha Institute of Technology \& Sciences, Telangana, India.

movements happening. A total of 580 of random samples were collected from KM0 until KM23 which is sufficient as stated in [15]. Questionnaire was conducted to gain the insight from the individuals, public and private agencies as well as the public who were involved directly or indirectly in this study. A series of questions was created with the reference of relevant questionnaire in determining the compliance of road users against the $30 \mathrm{~km} / \mathrm{hr}$ speed signs around school areas, According to Gay \& Diehl [16] questionnaire is a descriptive form of study and the number of respondents required comprised $10 \%$ from the sample population. Thus, with the population of 5958 school students and a sample population of 361 school students based on Krejcie \& Morgan table [17], a sample size of only $10 \%, 37$ students was adequate but this research collected sample of 90 random respondents. They are required to choice from a 5 point Likert scale from strongly agree to strongly disagree. The questions were in asked to understand in the aspect of signage effectiveness, possibility of noncompliance and the respondents encounter with accidents with regard to their gender

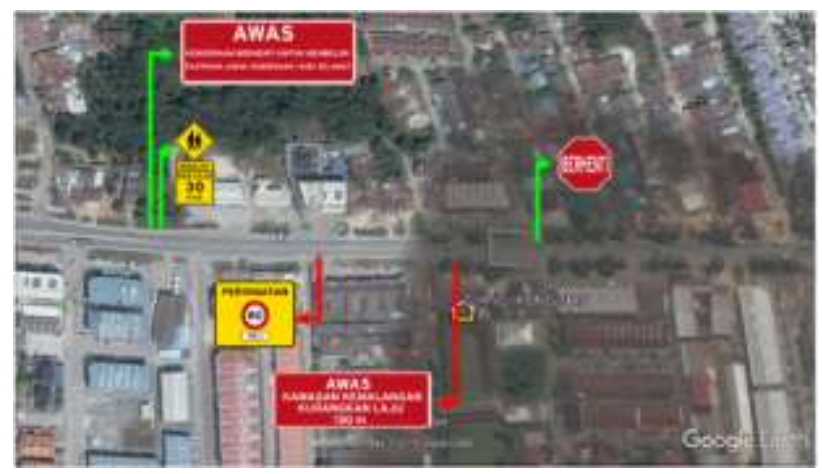

(a) SJK (C) KONG NAN

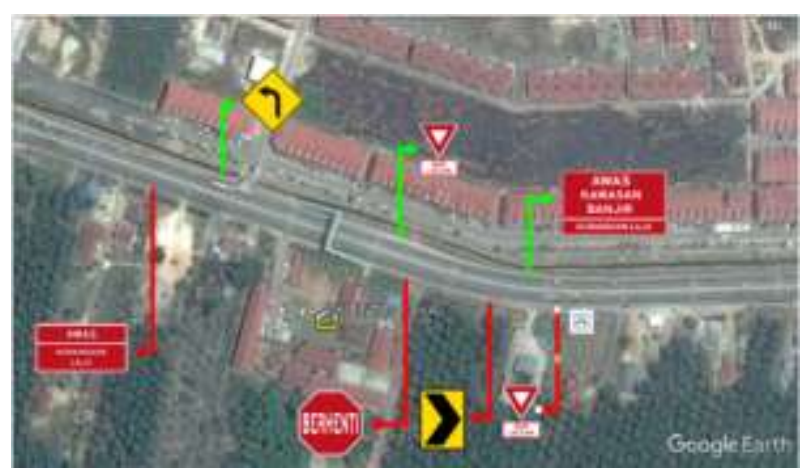

(c) SK PINTAS RAYA

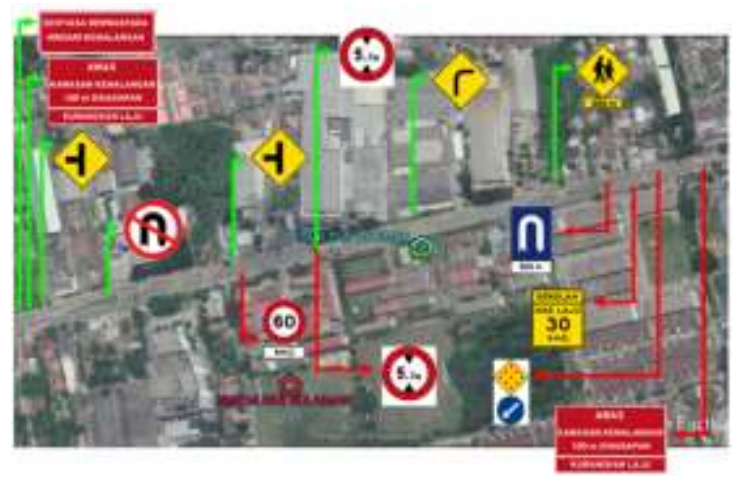

(e) SMK Munshi Sulaiman

(f) SMK TUN AMINAH

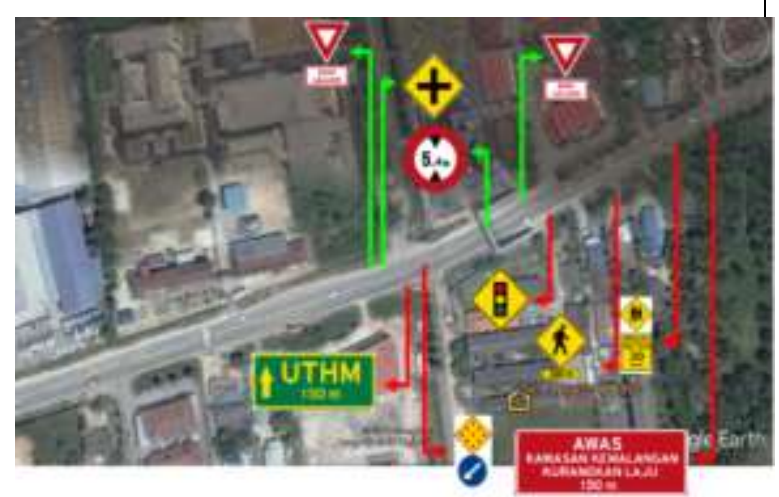

(b) SK PINTAS PUDING

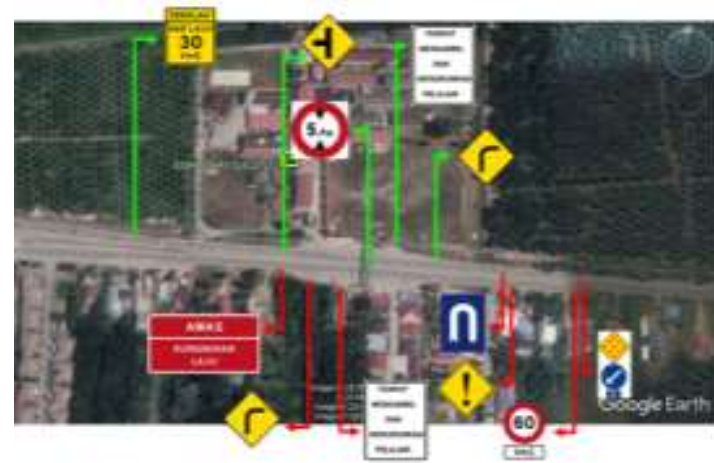

(d) SMK SERI GADING

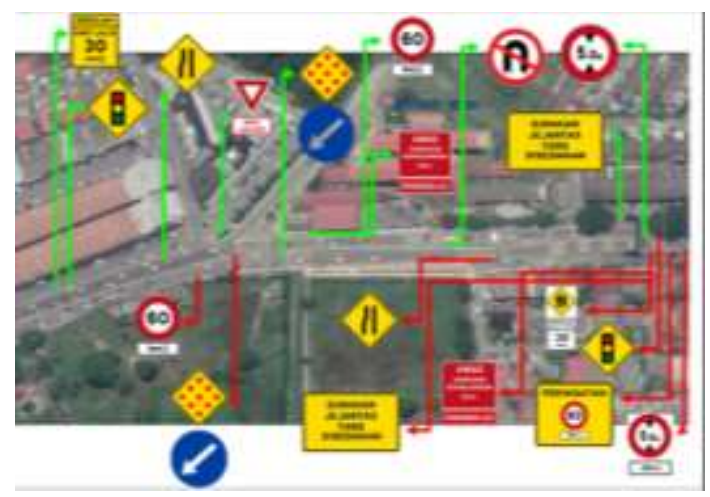

(g) SK BUKIT SOGA

Fig. 3. Installation of signage at school zones. Source: self-construct on google earth [19].

\section{RESULT AND DATA ANALYSIS}

From the site visit to the 7 school locations, SJK (C) Kong Nan, SK Pintas Puding, SK Pintas Raya, SMK Seri Gading, SMK Munshi Sulaiman, SMK Tun Aminah and SK Bukit Soga, Fig. 3 was constructed to illustrate the installation of signage. The observations gained from visiting the actual signage installation on site shows that the signage were placed at obscured location and not conspicuous, being obstructed by object such as trees. Besides, from the site visit, it can be seen that there were 
inadequate amount of signage placing to relay the speed limit as shown in Fig. 3. The existing signage were placed too closed to the school and were not at the distance for the placing of signage as recommended in Fig. 4 some of the signage did not have the same colour as in the design guide.

At SMK Seri Gading, there is a $60 \mathrm{~km} / \mathrm{h}$ speed limit sign placed in the school zone which is confusing to the road users. There are also location where signage were placed at the roadway directly in front of the school but not at the opposite lane where there are students crossing across the school which will lead to pedestrians not crossing the road in a safe manner that will danger their lives [18]

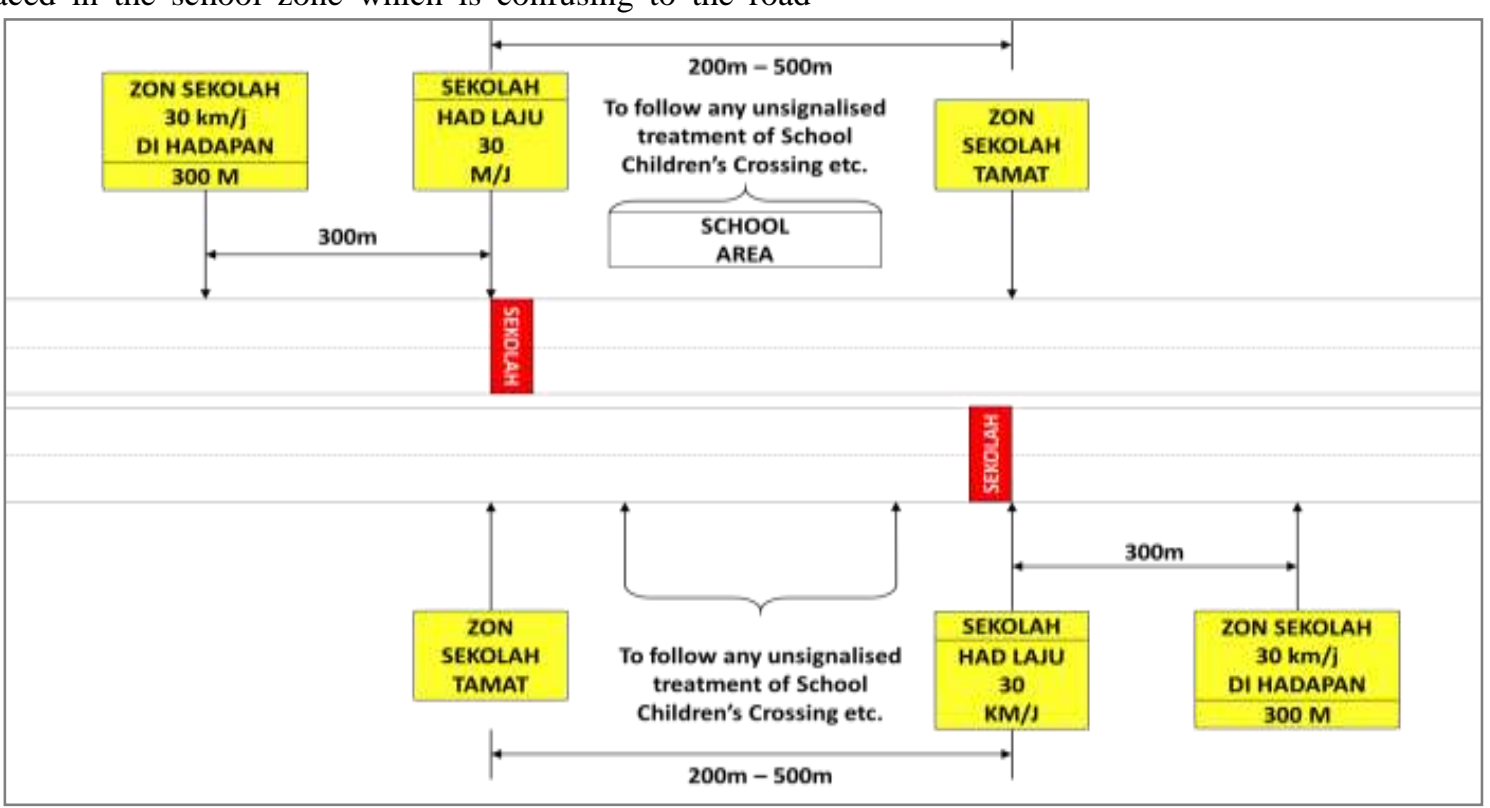

Fig. 4. Standard design plan for signage in school zone. Source [2]

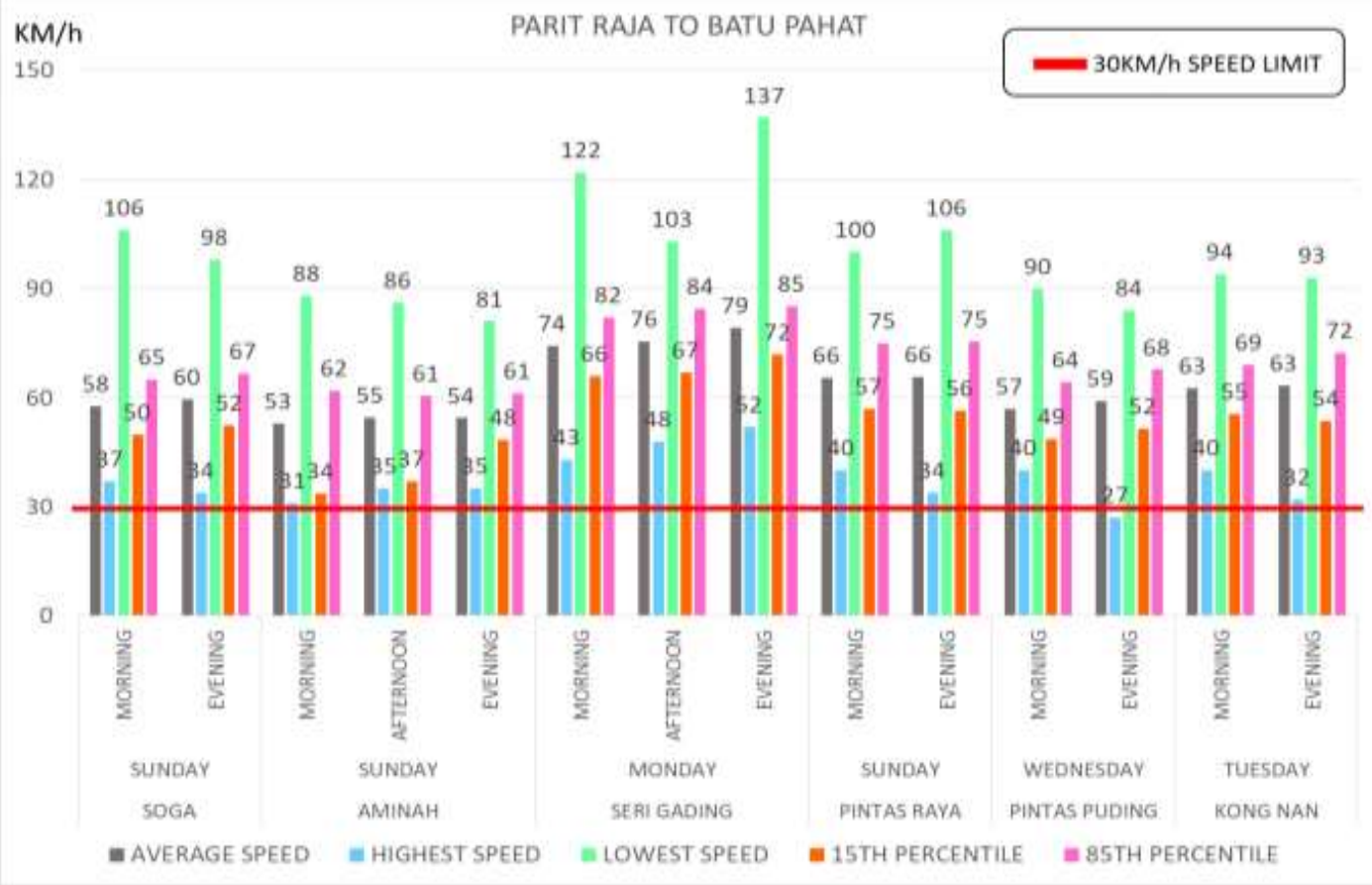

(a) 


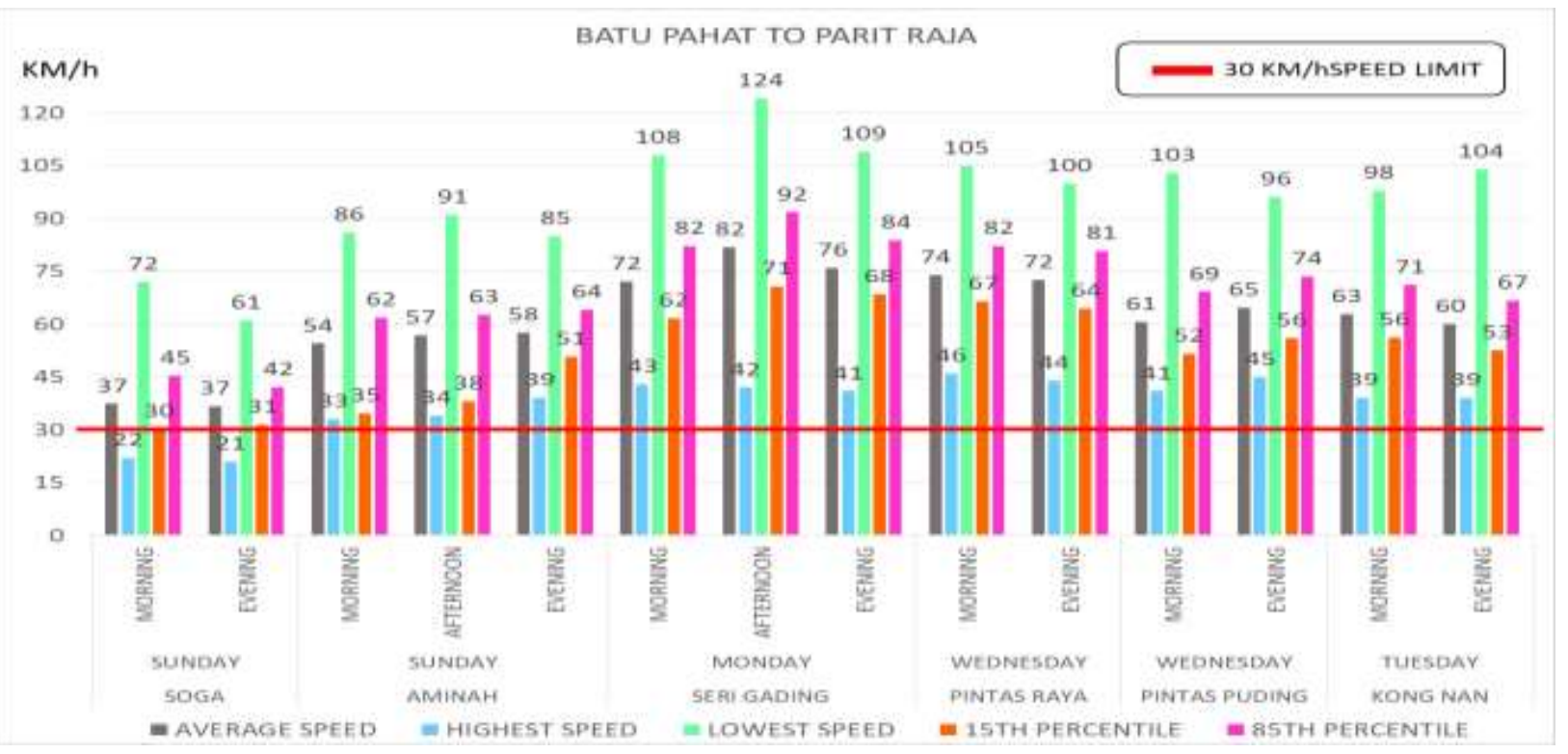

(b)

Fig. 5. Spot speed of (a) Parit Raja Batu Pahat (b) Batu Pahat Parit Raja.

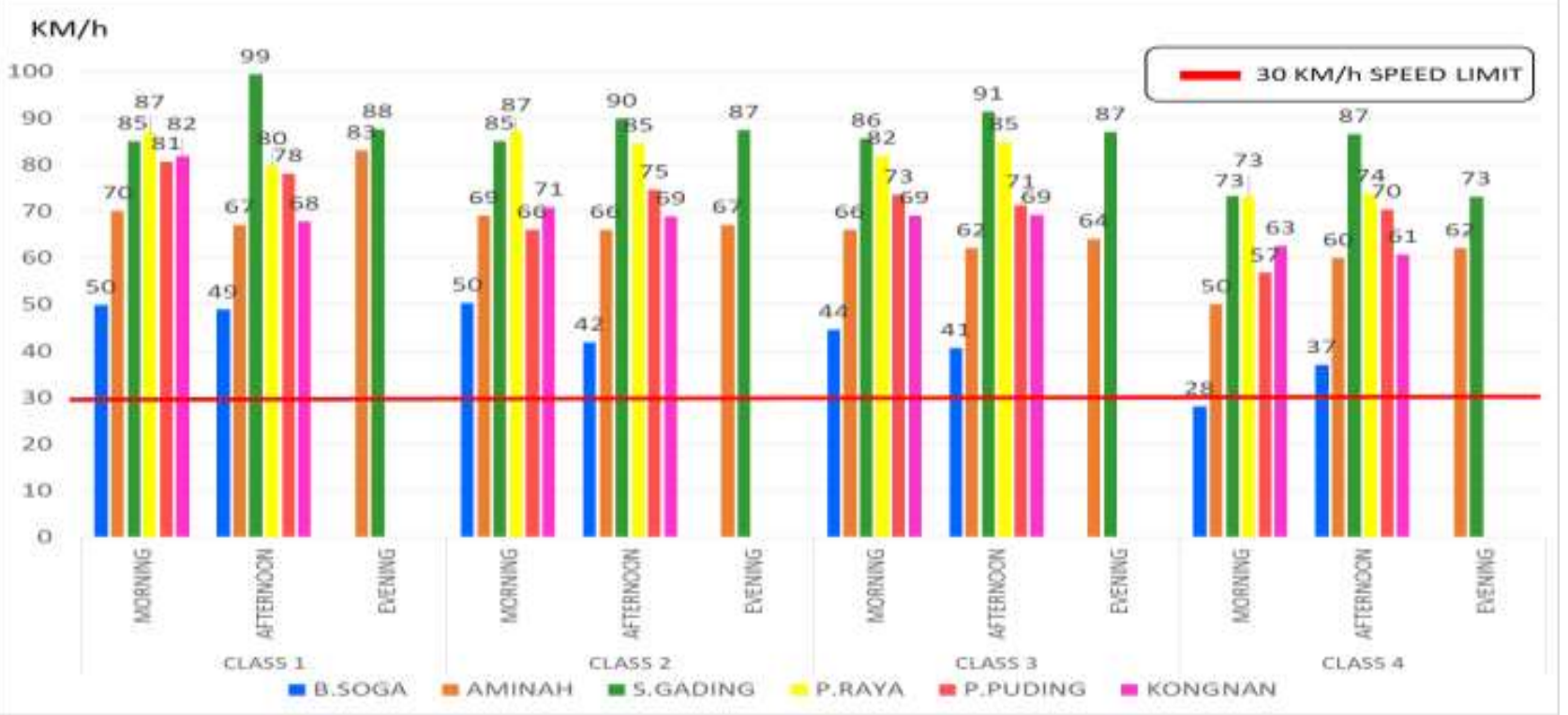

Fig. 6. $85^{\text {th }}$ percentile speed with the vehicle class of each school from Batu Pahat to Parit Raja

The same path of the return route from Parit Raja Batu Pahat, the analysis produced in Fig. 6 above. Using the same analysis method as the opposite path of Batu Pahat Parit Raja, the results also show a similar trend for the mean speed at respective schools and class type. As shown in Fig. 6, SMK Tun Aminah, SMK Munshi Sulaiman and SMK Seri Gading were the only three schools with record of two peak hours in the morning and afternoon because of the schooling schedules. For so, once again the average highest speed was recorded at SMK Seri Gading at $99 \mathrm{~km} / \mathrm{h}$ for vehicle class one (motorcycles) and vehicles class three. The $85^{\text {th }}$ percentile analysis shows the vehicle speed for each class of vehicles at SJK (C) Kong Nan, SK Pintas Raya, SK Pintas Pudding and SMK Seri Gading more than twice the speed limit of $30 \mathrm{~km} / \mathrm{h}$ in school zones. Thus, $85^{\text {th }}$ percentile of all the vehicles in seven school shows $100 \%$ of the drivers did not comply with the speed limit of $30 \mathrm{~km} / \mathrm{h}$ in school zones.
During the on-site observation, there were many instances where human inappropriate behaviour on road that can easily results in accidents. There was a situation where the school bus stopped at the middle lane of a 3 lane road to let go of students because the far left lane was filled with private vehicles of parents letting go their children, the bus obstructed the flow vehicles approaching at a high speed caused the vehicles behind to a sudden stop or weaving to the far right lane. This unorganised situation was common in all the selected school location. Despite having seven school zones in the stretch of road with the speed limit of $30 \mathrm{~km} / \mathrm{hr}$, vehicles still approaching at speed more than $30 \mathrm{~km} / \mathrm{hr}$. The habit of weaving, tailgating and red running can be seen frequently happening during site observation. 
Table 1. T-test result on the questionnaire survey

\begin{tabular}{|c|c|c|c|}
\hline & Questions & meall & I-test gig, ralue, $\mathrm{p}$ \\
\hline Q1 & 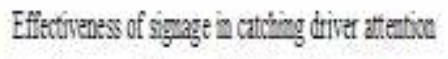 & 4.10 & 0.751 \\
\hline Q? & Conpliame with the sped liet of 30 ing ir & 1.05 & 0.003 \\
\hline Q3 & Do not experience wish accident encoumter & 1.34 & 0.043 \\
\hline
\end{tabular}

From the questionnaire survey of 90 respondents, 47 were males and 43 were females. All of them were local residents who were familiar with the traffic condition and route, they were above 18 years old with $87 \%$ possess driving license. T-test analysis was used to analyse the findings from the questionnaire data with the confidence level of $95 \%$ interval and error of 0.05 . Overall respondents paid attention to the speed limit signage of $30 \mathrm{~km} / \mathrm{h}$ in school zones as shown in Table 1. The study found that the effectiveness of speed limit signage of $30 \mathrm{~km} / \mathrm{h}$ in school zones was not affected by the gender of the respondents with p-value more than 0.05 . Whereby, regardless female or male drivers, they were aware of the speed limit and signage. Further analysis show the non-compliance regarding speed limit in school zones was influenced by the gender of the respondents $\mathrm{p}=0.03$ < 0.05 , where majority of them are male drivers. This shows males tend to violate the speed limit set which is similar with the previous study where masculine people then to show more aggressive driving [9]. The question on the experience of the respondents of meeting in an accidents when passing through a $30 \mathrm{~km} / \mathrm{h}$ speed limit of school zones, a p-value of $0.043, \mathrm{p}<0.05$ indicates that accidents occurred in school zone were related to the gender of the respondents in complying with the speed limit. This most possible explanation to this occurrence is due to the human behaviour of the respondents, they were familiar with the route as they commute every day for work and school. With the hectic situation of the traffic will elevate their emotional trait of anger, leading them to reckless and aggressive driving that increases the potential of accidents on the road.

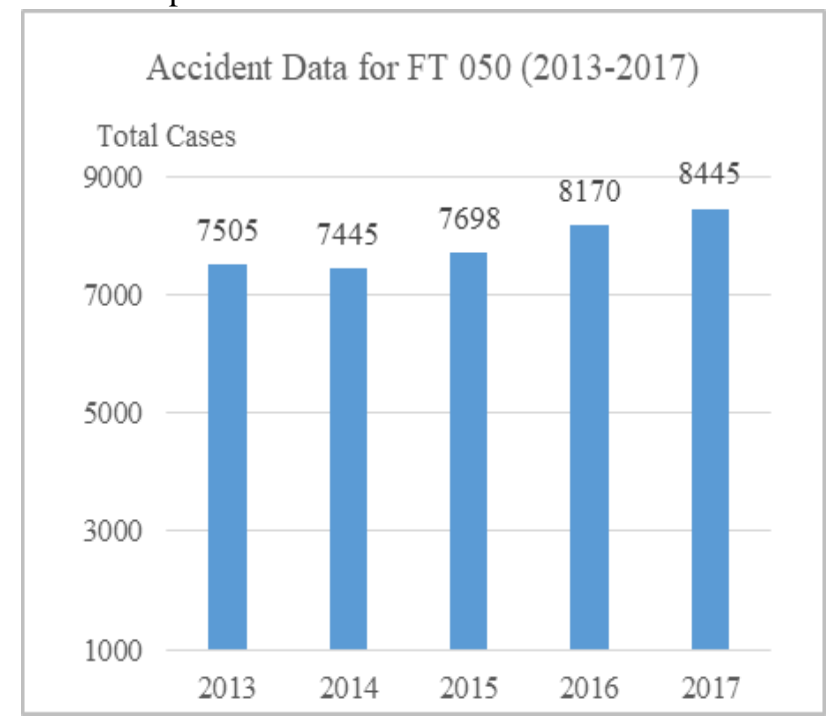

(a)

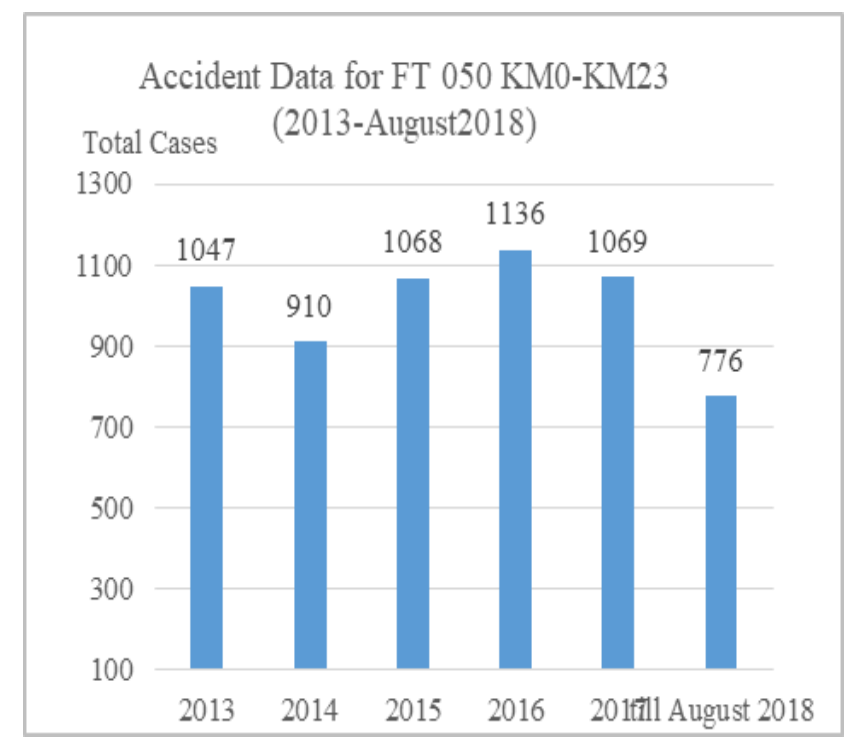

(b)

Fig. 7. Accident data for (a) FT050 from year 2013 to 2017 (b) KM0 to KM23 of FT050 from year 2013 to August 2018

Fig. 7 (a) and (b) are the accident data from the year 2013 to August 2018 received from the Royal Malaysian Police of Batu Pahat [1] for the route FT050 and for the distance KM0-KM23 respectively. Fig. 7 (a) shows the fluctuating accidents trend with gradually increasing number of accidents each year in the federal route FT050. Starting at the year 2013, the number of accidents was 7505 cases followed by a slight reduction to 7445 cases in 2014. Then for all the coming years, there is a constant increase of road accidents cases. Most severe number of accidents was in year 2017 with a total of 8445 cases on federal road FT050 and in August 2018, within a month period there is 972 cases. The accident trend for KM0-KM23 in Fig. 7 (b) also fluctuating over the period of 2013 and 2018. From the year 2013 of 1047 cases to 910 cases in 2014 a drop of 137 cases, then the gradually increase from year 2014 to 2016 with the record of 1068 cases in year 2015 and 1136 cases in year 2016. Then the number of accidents lower to 1069 cases in the 2017 and up to date of the research in the month of August there was already 776 cases. This data shows the high accident rates in school zone despite having posted speed limit erected in this area which is a concerning issue with the compliance of road users when driving in a $30 \mathrm{~km} / \mathrm{h}$ speed limit.

\section{SUMMARY}

In conclusion, this study investigated the compliance of road users with the $30 \mathrm{~km} / \mathrm{h}$ statutory speed limit and the posted speed limit with speed limit signage installed in the school zone in federal road FT050 from KM0 to KM 23. The driving speeds when passing through the 7 schools stated were above the $85^{\text {th }}$ percentile and were going at the speed twice the allowable speed of $30 \mathrm{~km} / \mathrm{h}$ which results in the high accident rates reflected in this area. The potential contributing factor to the non-compliance toward speed limit signage is the installation of signage do not follow the

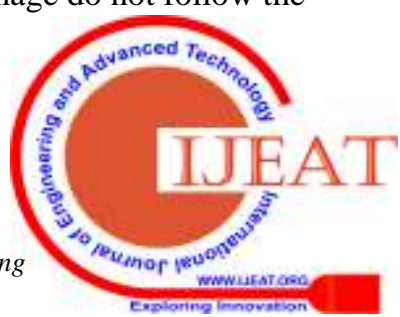


Malaysian standard of design guidelines on safety facilities for schools. From the perspective of human behaviour, the road users were aware of the speed limit in school zone and agreed to the installation of speed limit signage. However, they driving behaviour on road contradicting to the ideal driving environment as seen in the speed analysis in this study where majority of the road users are driving more than the speed limit which they unable to comply with the speed limit of $30 \mathrm{~km} / \mathrm{h}$ in school zone.

\section{ACKNOWLEDGMENT}

This research work is supported by Research Management Center (RMC) research grant TIER 1 [vote number: H220] Universiti Tun Hussien Onn Malaysia.

\section{REFERENCES}

1. Ahmad Abbaszaadeh, Barat Ghobadian, Mohammad Reza Polis DiRaja Malaysia (PDRM) Cawangan Batu Pahat., Accident statictics. 2018.

2. Jabatan Kerja Raya Malaysia, Panduan Merekabentuk Fasiliti Keselamatan Sekolah (NTJ 30/2015). 2015.

3. Jabatan Kerja Raya Malaysia, Panduan Pemilihan Had Laju (NTJ 30/2016). 2016.

4. Australia Department of Infrastructure Transport Regional Development and Local Goverment Austroads, Road Safety Audit. 1994.

5. M. S. Nemmang and R. Rahman, "An Overview of vehicles lane changing model development in approaching at u-turn facility road segment." J. Teknol., vol. 78, pp. 59-66, 2016.

6. Jabatan Kerja Raya Malaysia, Guidelines for the Selection of Speed Limit NTJ 34/2016. 2016.

7. L. Strawderman, M. Rahman, Y. Huang, and A. Nandi, "Driver behavior and accident frequency in school zones : Assessing the impact of sign saturation," Accid. Anal. Prev., vol. 82, pp. 118-125, 2015.

8. P. Colonna, P. Intini, N. Berloco, and V. Ranieri, "The influence of memory on driving behavior: How route familiarity is related to speed choice. An on-road study," Saf. Sci., vol. 82, pp. 456-468, 2016.

9. J. Albentosa, A. N. Stephens, and M. J. M. Sullman, "Driver anger in France: The relationships between sex, gender roles, trait and state driving anger and appraisals made while driving," Transp. Res. Part F Psychol. Behav., vol. 52, pp. 127-137, 2018.

10. B. Gregory, J. D. Irwin, I. J. Faulks, and E. Chekaluk, "Differential effects of traffic sign stimuli upon speeding in school zones following a traffic light interruption," Accid. Anal. Prev., vol. 86, pp. 114-120, 2016.

11. M. Rahman and L. Strawderman, "The Effect of Sign Saturation on Driver Speed Limit Compliance in School Zones," no. November, 2015.

12. N. Hidayati, R. Liu, and F. Montgomery, "The Impact of School Safety Zone and Roadside Activities on Speed Behaviour: the Indonesian Case," vol. 54, pp. 13391349, 2012.

13. B. D. Daniel, K. Ambak, J. Prasetijo, Y. M. Aman, M. Mohamad Taher, and M. Abdullah, Traffic Engineering. UTHM Publisher, 2016.

14. N. Mashros, R. Rahman, and J. Ben-edigbe, "Exploration of Sample Quantiles and Mean Speed Distributions," no. July 2015, 2012.

15. Y. Hou, C. Sun, and P. Edara, "A statistical test for 85th and 15th percentile speeds using the asymptotic distribution of sample quantiles," in The 91st Annual Meeting Of The Transportation Research Board Of The National Academies, 2012, vol. 2279, pp. 47-53.
16. L. R. Gay and P. L. Diehl, Research Methods for Business and Management. New York: Macmillan, 1992.

17. R. V. Krejcie and D. W. Morgan, "Determining sample size for research activities. Educational \& Psychological Measurement," vol. 30, pp. 607-610, 1970.

18. M. A. M. Bilema, M. M. Haurula, and R. Rahman, "The Study of Relationship Between Pedestrian and Safety based on the Theory of Planned Behaviour at Batu Pahat , Johor," MATEC Web Conf., vol. 103, p. 08010, 2017.

19. Google earth, "SJK (C) Kong Nan, SK Pintas Puding, SK Pintas Raya, SMK Seri Gading, SMK Munshi Sulaiman, SMK Tun Aminah and SK Bukit Soga," 20th September $2018,2018$. 